\title{
Corrigendum: Versatility of the complement system in neuroinflammation, neurodegeneration, and brain homeostasis
}

\author{
Franca Orsini ${ }^{1}$, Daiana De Blasio ${ }^{1,2}$, Rosalia Zangari ${ }^{1,3}$, Elisa R. Zanier ${ }^{1}$ and \\ Maria-Grazia De Simoni ${ }^{1 *}$ \\ ${ }^{1}$ Department of Neuroscience, IRCCS - Istituto di Ricerche Farmacologiche Mario Negri, Milan, Italy, ${ }^{2}$ Department of \\ Experimental and Clinical Sciences, University of Chieti, Pescara, Italy, ${ }^{3}$ Department of Anesthesia and Critical Care \\ Medicine, Fondazione IRCCS Ca' Granda Ospedale Maggiore Policlinico, University of Milan, Milan, Italy
}

Keywords: complement system, therapeutic targets, endothelium, stroke, traumatic brain injury, Alzheimer's disease, brain homeostasis

\section{A Corrigendum on}

\section{OPEN ACCESS}

Edited and reviewed by: Arthur Liesz,

University Hospital Munich, Germany

*Correspondence: Maria-Grazia De Simoni, desimoni@marionegri.it

Received: 15 June 2015 Accepted: 24 June 2015

Published: 07 July 2015

Citation:

Orsini F, De Blasio D, Zangari $R$ Zanier ER and De Simoni M-G (2015)

Corrigendum: Versatility of the complement system in neuroinflammation,

neurodegeneration, and brain homeostasis.

Front. Cell. Neurosci. 9:263. doi: 10.3389/fncel.2015.00263
Versatility of the complement system in neuroinflammation, neurodegeneration, and brain homeostasis

by Orsini, F., De Blasio, D., Zangari, R., Zanier, E. R., De Simoni, M. G. (2014). Front. Cell. Neurosci. 8:380. doi: 10.3389/fncel.2014.00380

In the funding statement one source of funding was missing. This is now rectified as follows:

\section{Acknowledgments}

The authors would like to thank Dr. Tracy K. McIntosh for carefully editing the manuscript. Financial support was provided by the Italian Ministry of Health, Young Investigators Award 2009 (GR-2008-1136044) and by Fondazione Cariplo (grant number 2012-0590). FO was funded by a fellowship in memory of Amalia Ghezzi.

Conflict of Interest Statement: The authors declare that the research was conducted in the absence of any commercial or financial relationships that could be construed as a potential conflict of interest.

Copyright $\odot 2015$ Orsini, De Blasio, Zangari, Zanier and De Simoni. This is an open-access article distributed under the terms of the Creative Commons Attribution License (CC BY). The use, distribution or reproduction in other forums is permitted, provided the original author(s) or licensor are credited and that the original publication in this journal is cited, in accordance with accepted academic practice. No use, distribution or reproduction is permitted which does not comply with these terms. 